\title{
Hubungan Amalan Pengurusan Kualiti ke atas Prestasi Organisasi PKS Industri Pemprosesan Makanan di Malaysia
}

\author{
Hayati Habibah Abdul Talib ${ }^{a^{*}}$, Khairul Anuar Mohd Ali ${ }^{\mathrm{b}}$, Fazli Idris ${ }^{\mathrm{b}}$ \\ ${ }^{a}$ UTM Razak School of Engineering \& Advanced Technology, Universiti Teknologi Malaysia, 54100 Kuala Lumpur, Malaysia \\ ${ }^{b}$ Graduate School of Business, Universiti Kebangsaan Malaysia, 43600 Bangi, Selangor, Malaysia \\ *Corresponding author: hayati@ic.utm.my
}

\section{Article history}

Received : 12 June 2012

Received in revised form : 1 January

2013

Accepted :15 February 2013

\begin{abstract}
Measurement of quality management practices is becoming more important in enhancing the holistic competitiveness in today's challenging market. Malaysia's food processing industry is rapidly growing and has contributed to the country's economic development. Malaysia is aiming towards the achievement to be world halal-hub as its potential has been identified. However, literature's on quality management practices and performance in this industry has indicated that, most of previous studies are focuses to the automotive and electrical industries. Thus, the research question on quality management practices and performance among these industry players in Malaysia are still unanswered. Questionnaires are used to gather information from SMEs in Malaysia's food processing industries through multistage sampling technique and a total of 221 questionnaires are returned. SPSS and AMOS 5.0 are used to analyze the relationship between this two latent constructs. The finding demonstrates the measured quality management practices are significant to the SMEs' organizational performance. The findings has highlighted the important factors of quality management practices and suggesting factors that need to be given attention by the food processing SMEs in order to gain excellence performance and be more competitive. Nevertheless, future studies are necessary to set forth and examine various factors that may affect the performance of SMEs in this industry.
\end{abstract}

Keywords: Quality management; critical success factor; organizational performance; SMEs; food processing industry; Malaysia

\begin{abstract}
Abstrak
Pengukuran amalan pengurusan kualiti menjadi semakin penting bagi memantapkan kebolehsaingan secara holistik dalam pasaran yang semakin mencabar. Industri pemprosesan makanan di Malaysia semakin berkembang maju dan turut menyumbang kepada pembangunan ekonomi negara. Malaysia juga mensasarkan pencapaian sebagai hub-halal dunia berikutan potensi baik bagi pasaran makanan halal dunia yang dikenal pasti. Namun, kajian kepustakaan berkenaan amalan pengurusan kualiti dan prestasi di industri ini menunjukkan bahawa majoriti kajian lepas lebih tertumpu kepada industri automotif dan elektrik. Dengan demikian, persoalan kajian berkaitan pelaksanaan amalan pengurusan kualiti dan prestasi di kalangan para pemain industri ini di Malaysia adalah masih belum terjawab. Borang soal selidik digunakan untuk mengumpul maklumat daripada PKS industri pemprosesan makanan di Malaysia menerusi kaedah pensampelan pelbagai peringkat dan sebanyak 221 borang soal selidik telah dikembalikan. SPSS dan AMOS 5.0 digunakan untuk menganalisis hubungan di antara kedua konstruk pendam kajian ini. Dapatan menunjukkan amalan pengurusan kualiti yang diukur adalah signifikan ke atas prestasi organisasi PKS. Dapatan kajian juga berjaya mengetengahkan faktor-faktor amalan pengurusan kualiti yang penting dan wajar diberi perhatian oleh PKS pemprosesan makanan bagi menikmati prestasi yang cemerlang dan lebih berdaya saing. Namun begitu, kajian masa hadapan perlu mengetengahkan dan menguji pelbagai faktor lain yang dapat mempengaruhi prestasi PKS di industri ini.
\end{abstract}

Kata kunci: Pengurusan kualiti; faktor kejayaan kritikal; prestasi organisasi; PKS; industri pemprosesan makanan; Malaysia

(c) 2013 Penerbit UTM Press. All rights reserved.

\subsection{PENDAHULUAN}

Industri pemprosesan makanan secara umumnya merupakan industri yang paling kurang terjejas daripada kesan perubahan ekonomi dunia. Keadaan ini dapat dilihat daripada nilai jualan produk makanan global yang turut dianggarkan bernilai AS\$3.5 trilion dan dijangka akan terus berkembang pada kadar 4.8 peratus setahun kepada AS\$6.4 trilion pada tahun 2020 (IMP3, 
2006). Tambahan pula, nilai dangangan eksport dan import bagi produk makanan bagi Malaysia turut dilaporkan semakin meningkat (MITI, 2008). Keadaan ini secara tidak langsung mewujudkan kesedaran tentang kepentingan dan potensi industri ini kepada pertumbuhan ekonomi negara. Selain itu, potensi pasaran yang wujud dalam industri ini juga membuka pelbagai peluang kepada para pengeluar produk makanan.

Industri pemprosesan makanan di Malaysia dipelopori oleh Perusahaan Kecil dan Sederhana (PKS) di mana, industri ini merupakan sektor perkilangan ketiga yang majoritinya diceburi oleh PKS selepas industri tekstil dan perabot (SMIDEC, 2006). Namun, umumnya PKS di Malaysia dilihat menghadapi masalah untuk bersaing dalam perdagangan ekonomi yang kebanyakkannya didominasi oleh sektor ekonomi besar tambahan pula, kekurangan sumber-sumber dan limitasi PKS turut menjadi penghalang kepada pembangunan industri pemprosesan makanan (Mohamad, 2004; IMP3, 2006). Maka, PKS industri ini perlu peka mengenal pasti dan bersedia menghadapi cabaran-cabaran yang ada agar lebih berdaya saing di pasaran di samping dapat meningkatkan prestasi yang lebih cemerlang dan seterusnya mampu meneruskan perniagaan dalam pasaran yang semakin mencabar. Kesan cabaran dari peningkatan liberalisasi dan persaingan dalam pasaran, telah mewujudkan iklim persaingan yang sengit namun, tidak semua syarikat mampu menghadapinya. Keadaan ini tidak mustahil turut dirasai oleh para pemain industri pemprosesan makanan yang majoritinya dipelopori oleh PKS yang sedia maklum menghadapi pelbagai kekakangan. Dengan demikian, setiap organisasi termasuk PKS tidak boleh menafikan bahawa tumpuan terhadap aspek kualiti merupakan elemen kritikal yang perlu diberi perhatian untuk bersaing dalam pasaran kini yang semakin mencabar. Tambahan pula, kualiti merupakan aspek utama bagi memastikan kejayaan syarikat-syarikat pengeluar untuk berjaya dalam pasaran (Besterfield, 1994; Barendsz, 1998; UNIDO, 2006).

Maka, perlaksanaan amalan pengurusan kualiti oleh PKS di industri ini di Malaysia adalah penting untuk lebih berdaya saing di pasaran yang semakin mencabar. Ini adalah selari dengan sasaran kerajaan Malaysia untuk menjadikan Malaysia sebagai hab halal. Oleh itu pembangunan dan perkembangan industri pemprosesan makanan dimantapkan melalui perancangan pelbagai program pembangunan oleh kerajaan Malaysia untuk membangunkan PKS di industri ini (IMP3, 2006; RMK9, 2006). Dengan demikian, kajian ini adalah amat penting dan wajar dilaksanakan bagi mengkaji amalan pengurusan kualiti yang dipraktikkan oleh PKS industri pemprosesan makanan. Selain itu, kajian ini adalah salah satu langkah proaktif sebagai persediaan bagi memperkasakan PKS agar dapat merebut peluang-peluang yang wujud serta bersedia menghadapi pasaran yang semakin mencabar. Mnuskrip terdiri daripada tiga bahagian utama perbincangan iaitu (i)Pendahuluan isu pemasalahan dan kajian kepustakaan; (ii) Bahan dan kaedah kajian; dan (iii) Hasil dan perbincangan dapatan kajian. Manakala, bahagian kesimpulan turut mencadangkan kajian masa hadapan.

\subsection{ISU PEMASALAHAN}

Terdapat beberapa isu-isu berkaitan indusri pemprosesan makanan di Malaysia yang dikenal pasti antaranya seperti bilangan syarikat pengeluar makanan yang memperolehi anugerah serta pensijilan kualiti adalah kurang memberangsangkan (JAKIM, 2008; MOH, 2009; MPC, 2010), halangan kemasukan produk makanan ke pasaran luar akibat kelemahan dari aspek kualiti (Zaihatun, 2003; Nor Aini et al.,
2007; Anon, 2008), amalan pengurusan yang tidak efisien (Nor Hasni, 2005; Pang \& Toh, 2008) dan sebagainya Berdasarkan kepada isu-isu yang telah dikenal pasti di peringkat awal kajian, dirumuskan bahawa pemasalahan utama yang dihadapi oleh PKS di industri ini adalah berkaitan dengan aspek pengurusan kualiti (Zaihatun, 2003; Nor Aini, 2004; Nor Hasni, 2005; IMP3, 2006; Anon, 2008; Pang \& Toh, 2008).

Adalah diyakini sekiranya isu-isu ini diambil mudah dan tidak ditangani dengan baik, pemasalahan ini akan menggugat prestasi organisasi PKS industri pemprosesan makanan di Malaysia. Dengan demikian, kajian ini menegaskan bahawa peningkatan prestasi PKS di industri ini sewajarnya tertumpu kepada aspek pengurusan kualiti yang berkaitan dengan pengurusan pengeluaran produk makanan yang suci, selamat dan berkhasiat. Pendapat ini dapat disokong bahawa, langkah permulaan yang paling bertepatan dilakukan untuk menghadapi cabaran pasaran produk makanan adalah bermula dengan pengukuran terhadap amalan pengurusan kualiti serta memberi tumpuan terhadap aktiviti berkaitan pengeluaran produk makanan (Golomski, 1993; Tybor et al., 1997; Dudbridge, 2011).

Dengan demikian, persoalan bahawa adakah PKS industri pemprosesan makanan di Malaysia melaksanakan amalan pengurusan kualiti bagi memenuhi keperluan kualiti dan menghadapi pasaran kini yang lebih mencabar, adalah masih belum terjawab. Maka, bagi tujuan kajian ini, kupasan berkaitan persoalan kajian tersebut memerlukan penjelasan lanjut dengan mengukur pelaksanaan amalan pengurusan kualiti serta impaknya terhadap prestasi organisasi PKS di industri ini. Bagi merungkai persoalan kajian ini, mengenal pasti konstruk amalan pengurusan kualiti dan prestasi adalah diperlukan bagi mengukur amalan pengurusan kualiti dan impaknya terhadap prestasi PKS di industri ini.Susun atur perbincangan di mulakan dengan membincangkan mengenai kajian kepustakaan berkaitan pengurusan kualiti dan seterusnya diikuti dengan kajian kepustakaan dan pembentukan konstruk yang digunakan untuk merungkai persoalan kajian. Seterusnya metodologi dan analisis kajian dibincangkan sebelum membawa kepada perbincangan dapatan dan kesimpulan kajian.

\subsection{KAJIAN KEPUSTAKAAN}

Falsafah amalan pengurusan kualiti menyeluruh (TQM) merupakan teori asas yang dirujuk bagi mengadaptasikan faktorfaktor kejayaan kritikal yang akan diukur untuk mengkaji amalan pengurusan kualiti di kalangan PKS industri pemprosesan makanan di Malaysia. Mengenal pasti konstrukkonstruk yang bersesuaian dalam kajian ini diperlukan untuk tujuan mengkaji hubungan di antara pelaksanaan amalan pengurusan kualiti berteraskan TQM di kalangan PKS industri ini dan hubungan dengan prestasi organisasi.

TQM diadaptasikan dalam kajian ini kerana TQM dan prestasi organisasi telah menjadi satu idea yang popular pada dekad ini untuk mengetahui pelaksanaan amalan pengurusan kualiti bagi meningkatkan daya saing syarikat dalam pesaingan pasaran (Quazi \& Padibjo, 1998; Yusof \& Aspinwall, 2000; Lakhal et al., 2006; Sharma \& Kodali, 2008; Pinho, 2008). Perlaksanaan TQM dapat memimpin PKS untuk melaksanakan amalan pengurusan kualiti yang baik bagi meningkatkan prestasi organisasi, penyediaan produk makanan yang berdaya saing dan seterusnya bakal menikmati peluang-peluang dalam pasaran. Pendekatan falsafah TQM dapat menggalakkan amalan perniagaan yang baik dan seterusnya dapat meningkatkan kecemerlangan perniagaan (Sharma \& Kodali, 2008; Pinho, 2008). Oleh itu, dalam iklim pasaran yang semakin mencabar 
ini, PKS industri pemprosesan makanan di Malaysia sewajarnya perlu lebih peka dalam usaha untuk meningkatkan kualiti produk menerusi amalan pengurusan kualiti secara menyeluruh.

Bagaimanapun, hasil perbandingan daripada pelbagai kajian kepustakaan di pelbagai negara berkaitan amalan pengurusan kualiti dan prestasi, kebanyakkan kajian berkaitan industri pemprosesan makanan adalah lebih tertumpu kepada bidang sains makanan dan sistem jaminan kualiti yang merangkumi aspek keselamatan dan kebersihanan makanan. Ini adalah seperti dikaji antaranya oleh Rohitratana dan Boon-itt (2001), Spiegel et al. (2003), Manning dan Baines (2004), Achilleas dan Anastosios (2008), Trienekens dan Zuurbier (2008), Karipidis et al. (2009) dan lain-lain. Selain itu, kajian kepustakaan amalan pengurusan kualiti di Malaysia menunjukkan bahawa masih kekurangan atau hampir tiada kajian yang dilaksanakan berkaitan amalan pengurusan kualiti dan prestasi organisasi industri pemprosesan makanan di Malaysia. Di mana, kebanyakkan kajian pengurusan kualiti adalah lebih tertumpu kepada industri automotif dan, elektrik dan elektronik. Terdapat juga kajian berkaitan pengurusan kualiti di kalangan PKS dilaksanakan dari sektor perkilangan secara umum.

Keperluan kajian secara sistematik terhadap amalan pengurusan kualiti dan kesannya terhadap prestasi PKS industri pemprosesan makanan di Malaysia adalah satu kajian yang penting untuk diterokai. Pendapat ini disokong dengan cadangan kajian masa hadapan oleh Lewis et al. (2006) yang menjelaskan bahawa, "Future research could validate critical factor and criteria identified for SMEs of different operational natures. In order to reveal sector-specific characteristics, case studies and comparative evaluations of TQM implementation in SMEs should be conducted across various industry sectors in developing countries". Penyataan ini dapat menyokong keperluan terhadap pelaksanaan kajian ini yang dapat menutupi jurang penyelidikan dalam bidang ilmu pengurusan kualiti di samping merungkai isu-isu berkaitan pengurusan kualiti di kalangan PKS selaku para pemain utama industri ini di Malaysia.

Kejayaan pelaksanaan amalan pengurusan kualiti adalah bergantung kepada beberapa kombinasi faktor kritikal dalam pelaksanaannya. Maka, bagi amalan pengurusan kualiti menyeluruh (TQM) yang diadaptasikan dalam kajian ini bagi mengukur status amalan pengurusan kualiti di kalangan PKS industri pemprosesan makanan di Malaysia adalah terdiri daripada lapan konstruk iaitu kepimpinan (LS), perancangan korporat $(\mathrm{CP})$, pengurusan sumber manusia (HRM), pengurusan maklumat (IM), fokus pelanggan (CF), fokus pembekal (SF), pengurusan proses (PM) dan jaminan kualiti (QA). Semua konstruk yang diketengahkan dalam kajian ini dikenal pasti daripada perbandingan beberapa kajian di bidang amalan pengurusan kualiti menyeluruh di pelbagai industri dan negara. Di mana, walaupun pelbagai kajian dan penyelidik mengetengahkan pelbagai jenis faktor kritikal bagi mengukur kejayaan pelaksanaan amalan pengurusan kualiti menyeluruh, namun hakikatnya faktor-faktor kritikal tersebut adalah terdiri dari satu kumpulan faktor yang biasa diketengahkan atau lebih dikenali sebagai common factors (Lewis et al., 2006; Sharma \& Kodali, 2008). Di mana semua konstruk amalan pengurusan kualiti ini adalah mewakli dimensi faktor kejayaan kritikal (CSF) yang akan diukur di kalangan PKS di industri ini di Malaysia.

Akibat pasaran global pada masa kini yang semakin mencabar, pengukuran ke atas prestasi organisasi turut menjadi semakin penting bagi mengekal kebolehwujudan perniagaan dalam pasaran (Brah et al., 2002; Yeung et al., 2005; Skrinjar et al., 2008; Parast et al., 2011). Selain itu, pengukuran prestasi diperlukan bagi mengenal pasti kejayaan pelaksanaan amalan pengurusan kualiti dalam organisasi telah tercapai (Wali et al., 2003; Parast et al., 2011). Dengan demikian, keperluan terhadap pengukuran prestasi adalah satu kewajiban bagi membolehkan organisasi mencapai prestasi yang diperlukan. Pencapaian prestasi yang memuaskan adalah bergantung kepada keberkesanan dan kejayaan amalan pengurusan kualiti, maka dengan itu, tumpuan terhadap pencapaian tersebut memerlukan pengukuran bagi tujuan penambahbaikan prestasi organisasi (Puay et al., 1998; Skrinjar et al., 2008).

Pengukuran prestasi dapat menyedarkan organisasi tentang bahagian-bahagian dalaman organisasi yang memerlukan perhatian dan penambahbaikan (Skrinjar et al., 2008; Kumar et al., 2009). Terdapat pelbagai tumpuan pengukuran prestasi yang dikaji dan ditonjolkan oleh kajian-kajian lepas, di mana, setiap pengukuran prestasi adalah berbeza dan pelbagai di antara kajian dengan kajian yang lain (Samson \& Terziovski, 1999; Kaynak, 2003; Skrinjar et al., 2008; Parast et al., 2011). Ini disokong bahawa, terdapat kajian yang mengukur kesan TQM ke atas prestasi perniagaan berdasarkan kepada pelbagai indikator pengukuran prestasi malahan terdapat juga pengukuran prestasi hanya berdasarkan kepada prestasi kewangan (Santos-Vijande \& Alvarez-Gonzalez 2007). Dengan demikian, pemboleh ubah yang digunakan untuk mengukur prestasi organisasi bagi kajian ini adalah berkaitan aspek kewangan dan bukan kewangan. Pengukuran prestasi organisasi PKS di industri ini adalah berdasarkan kepada pelbagai pengukuran prestasi organisasi seperti yang dilaksanakan antaranya oleh Kaynak (2003), Sila dan Ebrahimpour (2005), Feng et al. (2008), Su et al. (2008), Norhayati (2009), dan Parast et al. (2011), di mana, indikator yang diukur adalah terdiri daripada aspek kewangan dan bukan kewangan.

Merujuk kepada persoalan kajian yang telah dikenal pasti, kajian ini bermatlamat mengukur amalan pengurusan kualiti bagi mengetahui pelaksanaannya serta hubungannya ke atas prestasi organisasi PKS di industri pemprosesan makanan di Malaysia. Satu model konseptual telah dibangunkan bagi mengambar hubungan tersebur dan seterusnya sebagai panduan kepada penyelidik untuk mengukur setiap kontruk-konstruk bagi hubungan tersebut seperti yang ditunjukkan dalam Rajah 1. Seterusnya, hipotesis hubungan dibentuk bagi mengukur hubungan di antara dua konstruk digunakan dalam kajian ini bagi menjawab persoalan kajian. Hipotesis yang bangunkan adalah; Dimensi faktor kejayaan kritikal mempunyai hubungan ke atas prestasi organisasi PKS industri pemprosesan makanan di Malaysia. Di mana, hubungan tersebut mengukur hubungan antara dimensi faktor kejayaan kritikal (CSF) amalan pengurusan kualiti yang dapat mempengaruhi prestasi organisasi, ORGP. Secara tidak langsung, dapatan kajian ini dapat menggambarkan status pelaksanaan amalan pengurusan kualiti di kalangan PKS industri pemprosesan makanan di Malaysia dan dapatan kajian dapat dijadikan panduan oleh para PKS dalam memperbaiki amalan pengurusan kualiti dan peningkatan prestasi mereka. 


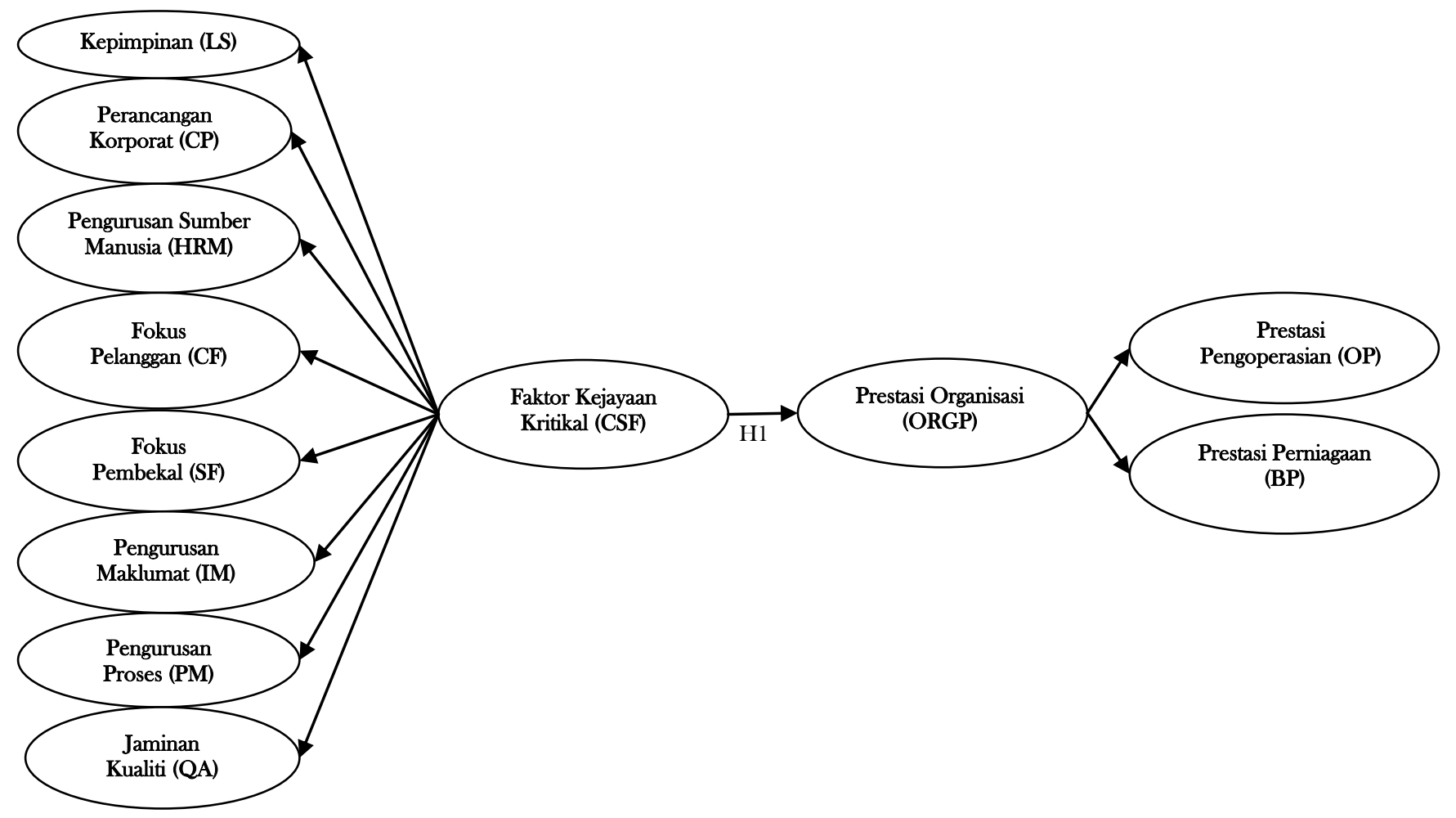

Rajah 1 Model konseptual kajian bagi mengukur amalan pengurusan kualiti dan prestasi PKS industri pemprosesan makanan di Malaysia

Jadual 1 Ringkasan CFA - kebolehpercayaan dan kesahan konstruk

\begin{tabular}{|c|c|c|c|c|c|c|c|}
\hline Konstruk & $\mathbf{N}$ & Bil Item & Min & $\begin{array}{c}\text { Sisishan } \\
\text { Piawai }\end{array}$ & $\begin{array}{c}\text { Alpa Cronbach } \\
(\alpha)\end{array}$ & $\begin{array}{c}\text { Kebolehpercayaan } \\
\text { Komposit (CR) }\end{array}$ & $\begin{array}{c}\text { Purata Varians } \\
\text { Diekstrakkan } \\
\text { (AVE) }\end{array}$ \\
\hline \multicolumn{8}{|l|}{ Dimensi CSF: } \\
\hline QA & 207 & 3 & 4.50 & 0.544 & 0.909 & 0.910 & 0.77 \\
\hline LS & 207 & 3 & 4.51 & 0.505 & 0.779 & 0.780 & 0.55 \\
\hline PM & 207 & 2 & 4.30 & 0.593 & 0.787 & 0.790 & 0.66 \\
\hline IM & 207 & 3 & 3.91 & 0.706 & 0.825 & 0.830 & 0.62 \\
\hline HRM & 207 & 2 & 4.22 & 0.594 & 0.700 & 0.700 & 0.54 \\
\hline $\mathrm{CF}$ & 207 & 3 & 4.15 & 0.532 & 0.773 & 0.780 & 0.53 \\
\hline SF & 207 & 3 & 4.42 & 0.506 & 0.774 & 0.790 & 0.56 \\
\hline $\mathrm{CP}$ & 207 & 3 & 3.94 & 0.652 & 0.737 & 0.740 & 0.50 \\
\hline \multicolumn{8}{|l|}{ Dimensi ORGP: } \\
\hline BP & 207 & 4 & 4.30 & 0.546 & 0.870 & 0.875 & 0.719 \\
\hline $\mathrm{OP}$ & 207 & 3 & 4.40 & 0.511 & 0.879 & 0.884 & 0.639 \\
\hline
\end{tabular}

\subsection{BAHAN DAN KAEDAH}

Borang soal selidik dibangunkan dan digunakan untuk mengumpul maklumat mengenai pelaksanaan amalan pengurusan kualiti di kalangan PKS industri ini. Lima skala Likert pula digunakan untuk mengumpul persepsi responden terhadap item-item pengukuran bagi setiap konstruk pendam bermula dengan tahap skala " 1 -sangat tidak bersetuju" dan sehingga "skala 5-sangat bersetuju." Manakala, pemilihan sampel dilakukan daripada senarai PKS industri pemprosesan makanan di Malaysia yang dibekalkan oleh SMECorp dengan menggunakan kaedah persampelan pelbagai peringkat. Borang soal selidik ini perlu dijawab oleh Pengarah Urusan, namun, dalam keadaan tertentu kebebasan diberikan kepada Pengarah Urusan untuk menentukan wakil bagi pihaknya yang boleh terdiri daripada individu, yang dipercayai mempunyai pengetahuan mengenai amalan pengurusan kualiti dan prestasi organisasi PKS tersebut. Sebanyak 221 borang soal selidik telah dikembalikan namun, hanya 207 sahaja yang dapat digunakan pada analisis selanjutnya setelah tapisan data dilaksanakan. Merujuk Armstrong dan Overton (1977) dan Kaynak (2003), analisis bias dijalankan ke atas respon yang diperolehi bagi mengetahui perbezaan skor min bagi item-item pengukuran di antara dua kumpulan responden; awal dan lambat. Pengujian menunjukkan bahawa kedua-dua kumpulan tidak menunjukkan sebarang perbezaan yang signifikan pada paras keertian $95 \%$. Ini menunjukkan masalah bais tidak-respons adalah tidak kelihatan dalam data kajian ini.

Analisis faktor penerokaan (EFA) menggunakan analisis komponen utama (PCA) dengan putaran varimaks dan nilai eigen lebih besar dari 1 digunakan untuk menentukan konstruk dan item-item pengukuran. Dapatan menunjukkan bahawa 
komponen yang terhasil daripada PCA adalah sama seperti konstruk yang dicadangkan. Namun, item-item pengukuran bagi setiap konstruk telah ditentukan berdasarkan faktor bebanan dengan menimbangkan nilai 0.4 sebagai nilai minimum. Nilai yang sama juga digunakan untuk kejadian pertindanan item, bagi tujuan mengenal pasti item-item yang mengukur setiap komponen atau faktor. Pada keseluruhannya, hasil keputusan PCA menunjukkan bahawa (i) bagi dimensi CSF, terdapat lapan konstruk dengan 56 item pengukuran, manakala (ii) bagi dimensi ORGP, terdapat dua konstruk dengan 14 item pengukuran. Seterusnya, dapatan ini akan digunakan bagi melaksanakan analisis konfirmatori.

Analisis faktor konfirmatori (CFA) menggunakan Pemodelan Persamaan Struktur (SEM) dengan perisian Analysis Moment of Strucures (AMOS 5.0) dipraktikkan bagi mengesahkan setiap konstruk dan item-item bagi kedua-dua model pengukuran adalah melibatkan urutan pertama dan kedua. Bagi mendapatkan padanan model, beberapa indeks padanan baik dipertimbangkan. Dapatan analisis CFA urutan pertama menunjukkan kedua-dua model pengukuran bagi dimensi CSF dan dimensi ORGP telah mencapai padanan yang baik. Malahan, CFA urutan kedua bagi kedua-dua model pengukuran ini juga turut menunjukkan padanan yang baik dengan data kajian. Pengukuran kebolehpercayaan dan kesahan turut berjaya diperolehi yang mana ia bermaksud item-item pengukuran setiap konstruk boleh mengukur atau mewakili konstruk pendam yang diukur. Seterusnya keadaan ini membenarkan pengukuran model kajian SEM dilaksanakan, manakala, ringkasan dapatan analisis CFA ini adalah seperti ditunjukkan oleh Jadual 1.

Seterusnya, pengujian hipotesis kajian ini berdasarkan model SEM terbit daripada kombinasi daripada kedua-dua model pengukuran ini turut dilaksanakan menggunakan AMOS 5.0. Di mana, teknik ini mampu mengukur pelbagai hubungan di antara pemboleh ubah bersandar dan tidak bersandar bagi sesuatu kerangka kajian secara serentak (Bollen, 1989; Byrne, 2001; Hair et al., 2006; Meyers et al., 2006). Analisis SEM ini digunakan adalah untuk mengukur dan menentukan sama ada hubungan secara teori yang ditunjukkan menerusi hipotesis kajian yang dibentuk adalah benar-benar disokong oleh data kajian yang diperolehi (Skrinjar, et al., 2008; Norhayati, 2009; Hair, et al. 2006; Meyers, et al. 2006; Jang, 2010).

\subsection{HASIL DAN PERBINCANGAN}

Berdasarkan kepada analisis CFA, bagi model kajian SEM ini, terdapat dua model pengukuran pendam. Model pengukuran yang pertama iaitu dimensi CSF, mengandungi lapan konstruk pendam seperti QA, LS, CP, IM, HRM, CF, SF dan PM. Manakala, model pengukuran pendam kedua adalah dimensi ORGP yang mengandungi dua konstruk pendam iaitu prestasi perniagaan (BP) dan prestasi pengoperasian (OP) yang mengandungi item pengukuran kewangan dan bukan kewangan. Dimensi CSF adalah merupakan pemboleh ubah tidak bersandar (pemboleh ubah eksogen) dan dimensi ORGP (pemboleh ubah endogen) merupakan pemboleh ubah bersandar.

SEM digunakan adalah untuk mengukur dan menguji dimensi CSF amalan pengurusan kualiti yang terdiri daripada lapan konstruk, di mana, setiap konstruk mempunyai hubungan yang signifikan ke atas hubungan CSF amalan pengurusan kualiti terhadap prestasi organisasi PKS industri pemprosesan makanan di Malaysia. Model struktur hubungan bersebab seperti yang di paparkan oleh Rajah 1 adalah dirujuk bagi menguji hipotesis kajian yang telah dinyatakan di atas. Bagi kajian ini, statistik bagi indeks padanan baik (GOF) yang digunakan untuk mengukur padanan data bagi model hubungan
SEM yang dihipotesiskan adalah sama seperti yang digunakan untuk menguji model pengukuran (Kaynak, 2003; Saemah, 2004; Norhayati, 2009; Bacon, 2009; Jang, 2010). Pengujian hipotesis SEM adalah berbeza dengan pengujian hipotesis secara traditional, ini kerana matlamat analisis SEM adalah untuk mendapatkan keputusan GOF yang tidak signifikan (Shah \& Goldstein 2006). Di mana, padanan bagi model SEM kebiasaannya ia dinilai berdasarkan kepada nilai statistik khikuasa dua $\left(\chi^{2}\right)$. Jika nilai statistik khi-kuasa dua $\left(\chi^{2}\right)$ adalah signifikan iaitu nilai-p yang diperolehi lebih kecil dari 0.05 $(\mathrm{p}<0.05)$, ini menunjukkan bahawa padanan model yang lemah dengan data, yang bermaksud hipotesis yang diuji adalah tidak disokong oleh dapatan.

Walau bagaimanapun, nilai statistik ini terlalu sensitif terhadap bilangan saiz sampel (Bentler \& Bonett, 1980; Byrne, 2001; Hair et al., 2006; Meyers et al., 2006; Shah \& Goldstein, 2006; Arawati et al., 2009; Abdullah, et al. 2009). Selain itu, turut dicadangkan bahawa pengukuran model berdasarkan indeks padanan yang lain adalah perlu bagi menangani masalah berkaitan dengan bilangan saiz sampel ini, seperti, dengan mempertimbangkan nilai Goodness of fit index (GFI), Adjusted goodness of fit index (AGFI), Normalized fit index (NFI), Comparative fit index (CFI), dan Root mean square error of approximation (RMSEA). Dengan demikian, penerimaan GOF bagi sesuatu model adalah dengan melihat kepada model indeks padanan, GFI, AGFI, NFI dan CFI, yang nilainya perlu sama atau lebih besar daripada 0.09. Manakala, nilai RMSEA yang dapat diterima adalah sama atau lebih kecil daripada 0.08 (Byrne, 2001; Hair, et al., 2006). 


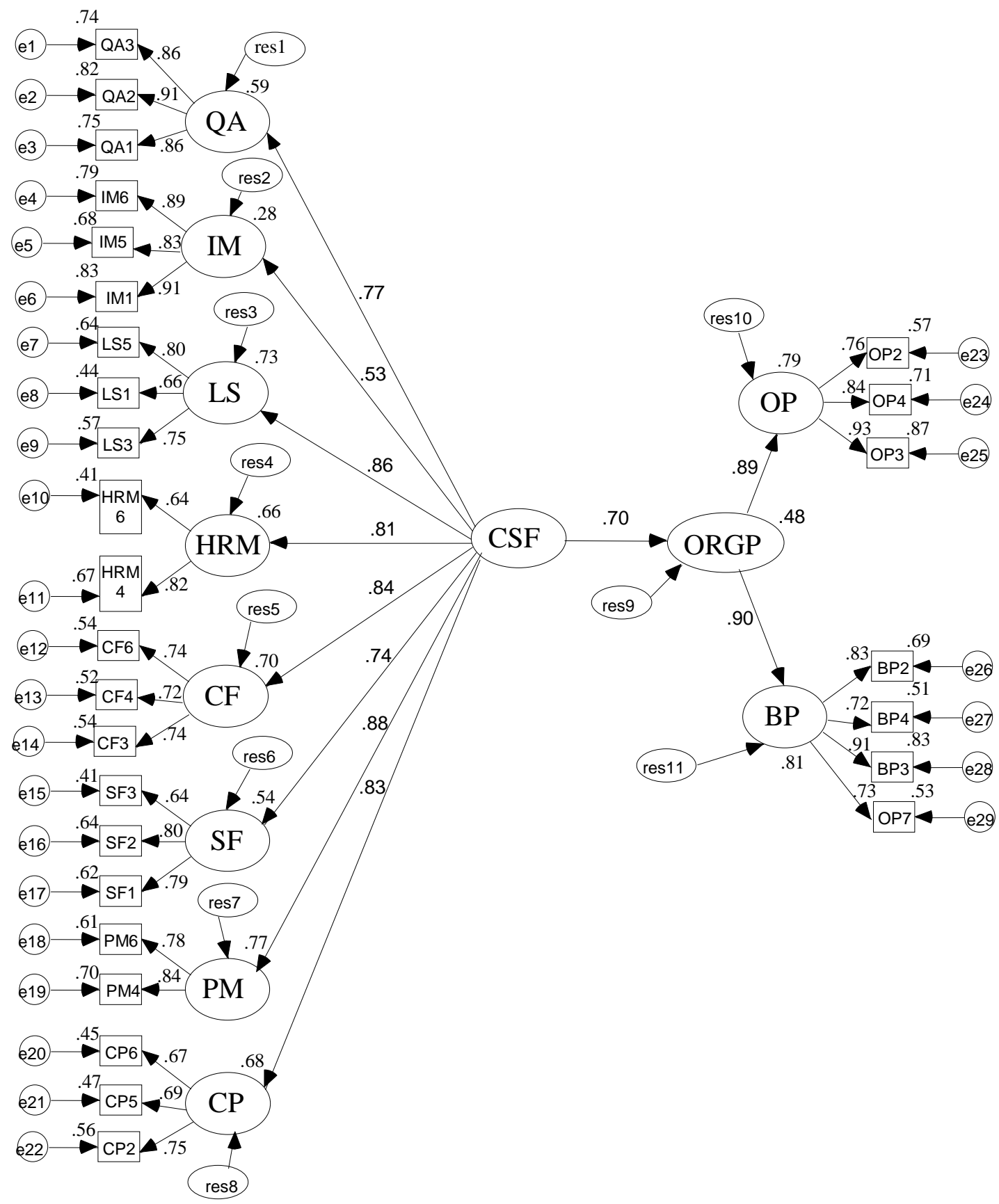

Rajah 2 Hubungan Permodelan Persamaan Berstruktur (SEM) antara dimensi CSF dan ORGP PKS industri pemprosesan makanan di Malaysia

Dengan merujuk kepada nilai indeks padanan yang dicadangkan, nilai indeks GOF menunjukkan model yang dihipotesiskan mempunyai nilai padanan yang baik terhadap data kajian. Merujuk kepada hipotesis kajian, hasil analisis SEM bagi model kajian ini menunjukkan bahawa indeks GOF model adalah dapat diterima. Di mana, nilai statistik khi-kuasa dua $\left(\chi^{2}\right)$ adalah $737.845(\mathrm{df}=367, \mathrm{p}<0.001)$, dengan nisbah $\chi^{2} / \mathrm{df}$ adalah 2.010 yang mana ianya lebih rendah daripada nilai statistik yang dicadangkan 3.0 menunjukkan bahawa indeks padanan yang baik. Manakala, nilai GFI $=0.820$, AGFI $=0.800, \mathrm{CFI}=0.894$ dan $\mathrm{TLI}=0.883$, walaupun nilai-nilai ini lebih rendah daripada nilai statistik minimum yang dicadangkan iaitu pada 0.90 , nilai-nilai ini adalah menghampiri nilai tersebut. Dapatan kajian ini sama seperti dapatan yang diperolehi dalam kajian yang dilakukan antaranya oleh Metts (2007), Su et al. (2008), Muslim (2009), dan Norhayati (2009). Sementara itu, model kajian ini juga memperolehi nilai RMSEA $=0.07$, yang mana ianya di bawah daripada nilai statistik yang dicadangkan, 0.08, dan ini menunjukkan bahawa indeks padanan yang amat memuaskan. Rajah 2 menggambarkan dapatan analisis SEM terhadap hubungan di antara CSF amalan pengurusan kualiti dan prestasi organisasi, ORGP.

Hasil analisis SEM ke atas hubungan di antara dimensi CSF amalan pengurusan kualiti dan dimensi ORGP di kalangan PKS industri pemprosesan makanan di Malaysia telah mencapai padanan. Pada keseluruhannya, nilai-nilai indeks padanan seperti yang ditunjukkan oleh Jadual 2 adalah menghampiri nilai minimum dan ini menunjukkan bahawa model tersebut adalah 
mempunyai padanan dengan data kajian. Dengan demikian, hipotesis kajian telah disokong oleh datapan kajian, iaitu $\mathrm{H} 1$ : Dimensi CSF amalan pengurusan kualiti memberi kesan terhadap dimensi ORGP PKS industri pemprosesan makanan di Malaysia, maka hipotesis kajian ini telah terjawab. Keadaan ini membawa maksud, bahawa semakin tinggi pelaksanaan konstruk-konstruk CSF amalan pengurusan kualiti berteraskan falsafah TQM oleh PKS, maka ia dapat memangkinkan peningkatan prestasi organisasi PKS industri ini di Malaysia. Dengan erti kata lain, konstruk-konstruk dimensi CSF amalan pengurusan kualiti merupakan pemangkin kepada peningkatan prestasi organisasi PKS industri pemprosesan makanan di Malaysia.

Jadual 2 Ringkasan indeks padanan bagi model SEM

\begin{tabular}{|c|c|c|c|}
\hline $\begin{array}{c}\text { Indeks Padanan Baik } \\
\text { (GOF) }\end{array}$ & $\begin{array}{c}\text { Indeks } \\
\text { Minimum } \\
\end{array}$ & Hasil Kajian & Ulasan \\
\hline 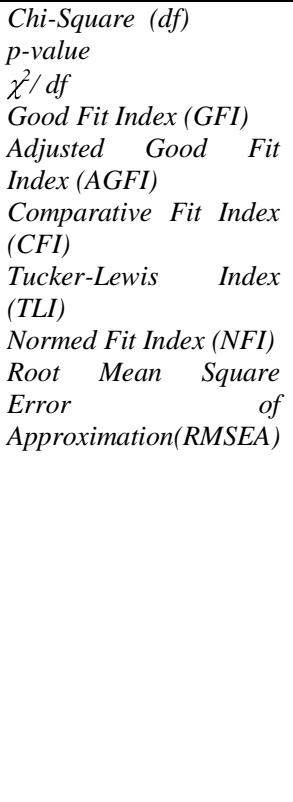 & $\begin{array}{l}\quad- \\
\geq 0.05 \\
\leq 3.0 \\
\geq 0.9 \\
\geq 0.8 \\
\geq 0.9 \\
\geq 0.9 \\
\geq 0.9 \\
\leq 0.08\end{array}$ & $\begin{array}{c}737.845(367) \\
0.000 \\
2.010 \\
0.820\end{array}$ & $\begin{array}{l}\text { GFI, CFI, TLI } \\
\text { dan NFI } \\
\text { adalah } \\
\text { menghampiri } \\
\text { nilai indeks } \\
\text { padanan, } \\
\text { manakala } \\
\text { nilai nisbah } \\
\chi^{2} / \text { df dan nilai } \\
\text { RMSEA } \\
\text { menunjukkan } \\
\text { nilai yang } \\
\text { memenuhi } \\
\text { indeks } \\
\text { padanan } \\
\text { minimum, } \\
\text { maka ini } \\
\text { menunjukkan } \\
\text { bahawa SEM } \\
\text { model SEM } \\
\text { adalah dapat } \\
\text { diterima dan } \\
\text { ianya padan } \\
\text { dengan data } \\
\text { kajian. }\end{array}$ \\
\hline
\end{tabular}

Model kajian ini menunjukkan bahawa setiap konstruk bagi dimensi CSF amalan pengurusan kualiti berdasarkan TQM mempunyai hubungan positif terhadap prestasi organisasi, ORGP, PKS industri pemprosesan makanan di Malaysia. Ini membuktikan bahawa CSF amalan pengurusan kualiti yang dicadangkan berdasarkan kepada pendekatan TQM adalah dapat diterima dan berguna sebagai alat pengukuran terhadap amalan pengurusan kualiti di kalangan PKS industri ini di Malaysia. Bagi kajian ini, merujuk kepada nilai pemberat regresi terpiawai bagi setiap konstruk dimensi CSF yang diperolehi, ia menunjukkan bahawa konstruk kritikal yang paling penting dalam mempengaruhi prestasi organisasi PKS di industri ini adalah PM (0.88), LS (0.86), CP (0.83), CF (0.84), HRM (0.81), QA (0.77), SF (0.74), dan IM (0.53), sama seperti yang ditunjukkan oleh Rajah 2.

Dengan demikian, kelapan-lapan konstruk dimensi CSF amalan pengurusan kualiti yang dikaji didapati memberi kesan signifikan terhadap peningkatan prestasi organisasi. Secara tidak langsung, membuktikan bahawa konstruk-konstruk faktor kejayaan kritikal, adalah penting diberi perhatian oleh PKS dalam meningkatkan prestasi organisasi mereka pada masa hadapan. Ini menunjukkan bahawa model konseptual kajian bagi mengukur pelaksanaan faktor kejayaan kritikal amalan pengurusan kualiti berdasarkan TQM adalah dapat diterima dan turut dipraktikkan oleh PKS industri pemprosesan makanan di Malaysia. Di mana, CSF amalan pengurusan kualiti dapat mempengaruhi prestasi organisasi sama ada prestasi pengoperasian mahupun prestasi perniagaan.

Namun begitu, seperti dibincangkan diperingkat awal kajian, terdapat limitasi yang dihadapi dalam kajian ini berikutan kekurangan kajian-kajian lepas berkaitan amalan pengurusan kualiti dan prestasi di sektor makanan. Akibat kesukaran mendapatkan rujukan daripada kajian-kajian lepas dalam bidang pengurusan kualiti khususnya di industri pemprosesan makanan, rujukan kepada pelbagai sumber kajian yang berkaitan di industri-industri lain digunakan sebagai panduan. Tindakan ini adalah selari dengan Beatty (2006) dan Karipidis et al. (2009), bahawa pelaksanaan amalan pengurusan kualiti di industri lain dapat dijadikan sebagai panduan bagi industri pemprosesan makanan memandangkan pengalaman pelaksanaan amalan pengurusan kualiti di industri makanan adalah terhad. Walau bagaimanapun, pelaksanaan setiap amalan pengurusan kualiti mungkin berbeza di antara satu industri dengan yang lain. Ini berikutan daripada persekitaran atau sifat bidang perniagaan yang berbeza (Brah, et al. 2002; Sila \& Ebrahimpour, 2005; Lewis et al., 2006). Tambahan pula, ianya disokong oleh Sila dan Ebrahimpour (2005), Lewis et al. (2006), Singh et al. (2006) dan juga oleh Lin dan Jang (2008), bahawa penerokaan terhadap teori dan amalan pengurusan kualiti secara menyeluruh perlu dilaksanakan di industri dan negara yang berbeza. Pengukuran terhadap faktor kritikal yang dikenal pasti bagi PKS di industri yang berbeza diperlukan untuk merungkai pelaksanaan amalan pengurusan kualiti di kalangan PKS dari pelbagai jenis industri khususnya bagi negara-negara sedang membangun.

Dapatan ini juga adalah selari dengan dapatan daripada kajian-kajian berkenaan amalan pengurusan kualiti yang telah dikaji dalam industri-industri lain (bukan makanan) di Malaysia antaranya seperti laporkan oleh Arumugam et al. (2008) yang mengukur amalan TQM terhadap prestasi kualiti yang dijalankan oleh syarikat perkilangan Malaysia yang memperoleh pensijilan ISO 9001:2001. Namun begitu, dapatan kajian beliau menunjukkan bahawa elemen TQM seperti kepimpinan, penglibatan pekerja, proses pengeluaran, analisis maklumat dan hubungan pembekal tidak mempunyai kesan yang signifikan terhadap prestasi kualiti. Selain itu, wujudnya hubungan positif di antara elemen TQM terhadap prestasi organisasi turut diperoleh oleh kajian yang dilaporkan oleh Norhayati (2009), di kalangan pengilang-pengilang industri automotif di Malaysia dan Thailand. Kajian beliau menunjukkan bahawa amalan TQM pengusaha automotif di kedua-dua negara mempunyai hubungan positif terhadap prestasi. Seterusnya, kajian oleh Abdullah et al. (2009) yang dilakukan di 255 buah syarikat industri elektrik dan elektronik (E\&E) di Malaysia menunjukkan bahawa kesemua enam elemen bukan teknikal TQM yang dikaji adalah secara positifnya mempunyai kaitan dengan prestasi organisasi.

Manakala, kajian-kajian daripada negara luar turut membincangkan hubungan antara faktor-faktor amalan pengurusan kualiti ke atas prestasi organisasi. Antara kajian yang dapat dibincangkan adalah seperti analisis terhadap hubungan pelaksanaan amalan TQM dan prestasi organisasi PKS yang dilaksanakan oleh Demirbag et al. (2006) di industri tekstil Turki yang turut menunjukkan hubungan yang signifikan ke atas prestasi organisasi. Prestasi organisasi yang diukur bagi kajian tersebut adalah berdasarkan kepada elemen kewangan dan bukan kewangan. Dapatan beliau membuktikan bahawa wujudnya hubungan positif yang kuat di antara amalan TQM dengan prestasi bukan kewangan PKS. Bagaimanapun, kajian beliau juga mendapati terdapat hubungan yang lemah di antara amalan TQM terhadap prestasi kewangan PKS. Dapatan yang 
sama juga turut diperoleh oleh kajian di firma Amerika Syarikat yang dilakukan oleh Kaynak (2003), bahawa wujudnya hubungan positif di antara amalan TQM dengan prestasi organisasi. Walau bagaimanapun, kajian beliau mendapati bahawa faktor amalan TQM yang mempunyai hubungan langsung terhadap prestasi pengoperasian adalah seperti hubungan pembekal, reka bentuk produk dan pengurusan proses. Ini disokong oleh dapatan kajian oleh Santos-Vijande dan Alvarez-Gonzalez (2007) di 93 buah syarikat yang beroperasi di Sepanyol Utara yang membuktikan bahawa TQM mempunyai hubungan positif terhadap prestasi. Beliau menegaskan bahawa, pelaksanaan dan membangunkan amalan TQM memerlukan komitment dan usaha kuat dari organisasi bagi mendapatkan hubungan positif ke atas prestasi.

Pada keseluruhannya, dimensi CSF amalan pengurusan kualiti di kalangan PKS industri pemprosesan makanan di Malaysia yang diukur menerusi lapan konstruk dapat dikategorikan kepada dua elemen iaitu amalan pengurusan kualiti bukan teknikal dan teknikal. Elemen bukan teknikal dan elemen teknikal amalan pengurusan kualiti secara menyeluruh, TQM, yang diterapkan dalam kajian ini memberikan peranan yang signifikan terhadap hubungan dimensi CSF ke atas ORGP PKS industri pemprosesan makanan di Malaysia, yang mana setiap konstruk ini mempunyai faktor bebanan, (pemberat regresi terpiawai), yang ditunjukkan adalah lebih besar daripada nilai 0.5 yang signifikan pada $\mathrm{p}<0.001$. Ini menunjukkan bahawa kedua-dua kategori elemen pengurusan kualiti teknikal dan bukan teknikal, mempunyai peranan dalam mempengaruhi prestasi organisasi PKS industri pemprosesan makanan di Malaysia. Tambahan pula, dapatan ini turut disokong melalui dapatan kajian yang dilaksanakan ke atas kedua-dua kategori amalan pengurusan kualiti terhadap prestasi organisasi antaranya di industri bukan makanan seperti kajian yang dilaksanakan seperti oleh Abdullah et al. (2009), Fotopoulos dan Psomas (2009), dan Gadenne dan Sharma (2009), yang mana, dapatan kajian yang diperolehi menunjukkan bahawa kedua-dua konstruk elemen bukan teknikal dan teknikal amalan pengurusan kualiti ini dapat membantu mempengaruhi prestasi organisasi.

Selanjutnya, berdasarkan kepada pemberat regresi terpiawai, analisis kajian ini menunjukkan bahawa kelapanlapan konstruk dimensi CSF amalan pengurusan kualiti yang dicadangkan bagi PKS industri pemprosesan makanan di Malaysia adalah signifikan terhadap dimensi CSF dan ianya menyumbang kepada pencapaian prestasi organisasi PKS di industri ini. Susunan kepentingan konstruk CSF berdasarkan kepada faktor bebanan yang ditunjukkan oleh setiap konstruk adalah PM (0.79), IM (0.79), LS (0.75), CF (0.74), CP (0.73), QA (0.72), HRM (0.67) dan SF (0.65), yang mana, setiap konstruk CSF ini adalah signifikan pada $\mathrm{p}<0.001$. Walaupun nilai faktor bebanan ini adalah agak sederhana, namun ianya membuktikan bahawa amalan setiap konstruk dimensi CSF adalah signifikan dan positif terhadap hubungan CSF dan ORGP PKS industri pemprosesan makanan di Malaysia. Dengan demikian, lapan sub hipotesis pertama, H1, iaitu H1a - H1h adalah disokong oleh dapatan kajian, iaitu, kelapan-lapan konstruk merupakan faktor penting kepada dimensi CSF amalan pengurusan kualiti di kalangan PKS industri pemprosesan makanan di Malaysia. Selain itu, ujian korelasi dilaksanakan antara konstruk pendam bagi kedua-dua dimensi pengukuran iaitu CSF dan ORGP. Dapatan korelasi seperti diringkaskan oleh Jadual 3, menunjukkan bahawa semua konstruk amalan pengurusan kualiti PKS industri pemprosesan makanan di Malaysia mempunyai hubungan positif yang signifikan terhadap dimensi CSF dan ORGP. Ini turut disokong oleh dapatan kajian yang dilakukan antaranya oleh Rad (2006), Fenning et al.
(2008), dan Kumar et al. (2009), bahawa setiap konstruk TQM dapat menyumbang kepada pencapaian prestasi organisasi. Seterusnya, penelitian dan perbincangan mengenai kepentingan setiap konstruk bagi dimensi CSF amalan pengurusan kualiti dalam kajian ini turut dilaksanakan bagi mengetahui pelaksanaan dan kepentingannya ke atas hubungan yang dikaji. Perbincangan ini dilaksanakan dengan melihat kepada nilai pemberat regresi terpiawai bagi setiap indikator atau faktor yang mengukur dimensi CSF amalan pengurusan kualiti. Dimulakan dengan pengurusan proses (PM), bagi kajian ini, faktor ini adalah merujuk kepada aspek yang terdiri daripada pelbagai aktiviti utama dalam proses pengeluaran produk termasuklah teknik kualiti, aktiviti penyelenggaran, penggunaan alatan dan mesin, penglibatan pekerja dalam pengeluaran serta aktiviti penambahbaikan (Tan 2002; Conca et al. 2004; Sila \& Ebrahimpour 2005; MPC 2010).

\subsection{KESIMPULAN}

Tujuan utama kajian ini adalah untuk menilai kesan dimensi CSF amalan pengurusan kualiti yang dibentuk berlandaskan falsafah TQM terhadap prestasi organisasi di kalangan PKS industri pemprosesan makanan di Malaysia. Teknik Permodelan Persamaan Berstruktur, SEM, digunakan untuk menguji hubungan antara pelaksanaan dimensi CSF amalan pengurusan kualiti dan prestasi organisasi. Menerusi analisis model hubungan bersebab SEM terhadap hubungan CSF dan ORGP PKS industri ini di Malaysia, dapatan menunjukkan bahawa model ini adalah sepadan dengan data kajian yang membawa kepada penyokongan terhadap hipotesis kajian. Selain itu, faktor bebanan yang ditunjukkan menerusi pemberat regresi terpiawai membuktikan bahawa setiap konstuk bagi dimensi CSF amalan pengurusan kualiti yang terdiri daripada kepimpinan (LS), perancangan korporat (CP), pengurusan sumber manusia (HRM), pengurusan maklumat (IM), fokus pelanggan $(\mathrm{CF})$, fokus pembekal (SF), pengurusan proses $(\mathrm{PM})$ dan jaminan kualiti (QA) menunjukkan hubungan signifikan terhadap dimensi CSF yang mempengaruhi ORGP PKS industri pemprosesan makanan di Malaysia.

Secara ringkasnya, keputusan analisis hubungan bersebab SEM, menunjukkan bahawa dimensi CSF amalan pengurusan kualiti berdasarkan kepada falsafah TQM seperti dicadangkan, didapati mempunyai impak yang signifikan terhadap prestasi organisasi PKS industri pemprosesan makanan di Malaysia. Selain daripada impak hubungan yang signifikan antara CSF amalan pengurusan kualiti terhadap dimensi ORGP, dapatan juga menunjukkan bahawa hubungan tersebut memberikan faktor bebanan yang sama ke atas dua konstruk pendam dimensi ORGP iaitu prestasi pengoperasian, OP dan prestasi perniagaan, BP, di mana faktor bebanan masing-masing ialah 0.89 dan 0.90 . Ini menunjukkan bahawa kedua-dua konstruk pendam ORGP ini adalah sama penting kepada prestasi PKS industri pemprosesan makanan di Malaysia menerusi kesan CSF amalan pengurusan kualiti yang dipraktikkan. Pada keseluruhannya, ini menunjukkan bahawa model konseptual kajian ini yang mengukur pelaksanaan CSF amalan pengurusan kualiti berteraskan TQM adalah dapat diterima dan dipraktikkan oleh PKS industri pemprosesan makanan di Malaysia. Ianya juga menunjukkan bahawa dimensi CSF amalan pengurusan kualiti turut mempengaruhi prestasi organisasi sama ada prestasi pengoperasian (OP) mahupun prestasi perniagaan (BP).

Selain itu, secara tidak langsung dapatan kajian ini turut menunjukkan bahawa amalan pengurusan kualiti secara menyeluruh turut dipraktikkan oleh PKS di industri ini seperti mana amalannya di industri lain. Walaupun wujudnya limitasi 
dalam konstruk-konstruk CSF dan ORGP yang ditentukan bagi industri ini di Malaysia, namun ianya telah dibuktikan menerusi analisis kajian ini secara empirikal bahawa wujudnya hubungan yang signifikan antara dimensi CSF amalan pengurusan kualiti dengan dimensi ORGP. Maka, dapatan ini telah berjaya membuktikan hubungan tersebut yang gagal ditonjolkan oleh kajian-kajian berkaitan amalan pengurusan kualiti sebelum ini. Namun, dapat dirumuskan bahawa pelaksanaan amalan pengurusan kualiti secara menyeluruh masih di peringkat awal dan memerlukan penambahbaikan bagi memantapkan pelaksanaannya dikalangan PKS industri pemprosesan makanan di Malaysia. Sumbangan yang dinikmati daripada kajian ini adalah mengetengahkan konstruk kritikal amalan pengurusan kualiti yang wajar diberi tumpuan oleh PKS di industri ini bagi memantapkan prestasi organisasi mereka disamping dapat menghasilkan produk makanan dengan kualiti yang dipercayai. Dengan demikian, dicadangkan kepada kajian masa hadapan untuk menambah konstruk kritikal serta item-item pengukuran amalan pengurusan kualiti yang bersesuaian bagi mendapatkan keputusan kajian yang lebih baik.

Jadual 3 Korelasi antara konstruk dimensi CSF dengan dimensi ORGP

\begin{tabular}{|c|c|c|c|c|c|c|c|c|c|c|c|c|c|}
\hline KONSTRUK & CSF & ORGP & QA & LS & $\mathrm{SF}$ & $\mathrm{CP}$ & $\mathrm{CF}$ & IM & PM & HRM & OP & & BP \\
\hline CSF & 1.000 & & & & & & & & & & & & \\
\hline ORGP & $.612^{* *}$ & 1.000 & & & & & & & & & & & \\
\hline QA & $.751^{* *}$ & $.529^{* *}$ & 1.000 & & & & & & & & & & \\
\hline LS & $.777^{* *}$ & $.517^{* *}$ & $.549^{* * *}$ & 1.000 & & & & & & & & & \\
\hline SF & $.702^{* *}$ & $.460^{* *}$ & $.473^{* *}$ & $.481^{* *}$ & 1.000 & & & & & & & & \\
\hline $\mathrm{CP}$ & $.793^{* *}$ & $.434^{* *}$ & $.464^{* *}$ & $.585^{* *}$ & $.470^{* *}$ & 1.000 & & & & & & & \\
\hline $\mathrm{CF}$ & $.778^{* *}$ & $.416^{* *}$ & $.505^{* *}$ & $.540^{* *}$ & $.486^{* *}$ & $.549^{* *}$ & 1.000 & & & & & & \\
\hline $\mathrm{IM}$ & $.831^{* *}$ & $.501^{* *}$ & $.563^{* *}$ & $.563^{* *}$ & $.473^{* *}$ & $.628^{* *}$ & $.588^{* *}$ & 1.000 & & & & & \\
\hline PM & $.790^{* *}$ & $.513^{* *}$ & $.623^{* *}$ & $.557^{* *}$ & $.510^{* *}$ & $.512^{* *}$ & $.616^{* *}$ & $.639^{* *}$ & 1.000 & & & & \\
\hline HRM & $.713^{* *}$ & $.399^{* *}$ & $.454^{* *}$ & $.521^{* *}$ & $.473^{* *}$ & $.545^{* *}$ & $.505^{* *}$ & $.518^{* *}$ & $.494^{* *}$ & 1.000 & & & \\
\hline $\mathrm{OP}$ & $.569^{* *}$ & $.894^{* *}$ & $.509^{* *}$ & $.425^{* *}$ & $.436^{* *}$ & $.390^{* *}$ & $.412^{* *}$ & $.461^{* *}$ & $.507^{* *}$ & $.373^{* *}$ & 1.000 & & \\
\hline BP & $.566^{* *}$ & $.949^{* *}$ & $.477^{* *}$ & $.517^{* *}$ & $.419^{* *}$ & $.410^{* * *}$ & $.366^{* *}$ & $.467^{* *}$ & $.453^{* *}$ & $.367^{* *}$ & $.708^{* *}$ & 1.000 & \\
\hline
\end{tabular}

\section{Rujukan}

Abdullah, M. M., Uli, J., \& Tari, J. J. 2009. The Importance of Soft Factors for Quality Improvement and Organizational Performance. International Journal Productivity and Quality Management. 4(3): 366-382.

Achilleas, K., \& Anastasios, S. 2008. Marketing Aspects of Quality Assurance Systems: The Organic Food Sector Case. British Food Journal. 110(8): 829-839.

Anon. 2008. Larangan EU: Negara rugi RM1.5 bilion setahun. Utusan Malaysia Online,13 Jun. http://www.utusan.com.my/utusan /arkib [16 Jun 2008.

Arawati Agus, Mhd. Suhaimi Ahmad \& Jaafar Muhammad. 2009. An Empirical Investigation on the Impact of Quality Management on Produtivity and Profitability: Associations and Mediating Effect. Contemporary Management Research. 5(1):77-92.

Armstrong, J. S. \& Overton, T. S. 1977. Estimating Nonresponse Bias in Mail Surveys. Journal of Marketing Research. 14: 396-402.

Arumugam, V., Ooi, K. B. \& Fong, T. C. 2008. TQM Practices And Quality Management Performance: An Investigation of Their Relationship Using Data from ISO 9001:2000 Firms In Malaysia. The TQM Magazine. 20(6): 636-650.

Bacon, Lynd, D. 2009. Using Amos for structural equation modelling in market research. Technical Report. SPSS Inc. http://www.SPSS.com/media/whitepapers/ AMOSMRPWP.pdf [25 Julai 2010].
Barendsz, A. W. 1998. Food Safety and Total Quality Management. Food Control. 9(2): 163-170.

Beatty, J. R. 2006. The Quality Journey: Historical and Workforce Perspectives and the Assessment of Commitment to Quality. International Journal Productivity and Quality Management. 1(1/2): 139-166.

Bentler, P. M., \& Bonett, D. G. 1980. Significance Test and Goodness of Fit in the Analysis of Covariance Srtructures. Psychological Bulletin. 88: 588-606.

Besterfield, D. H. 1994. Quality Control. Ed. ke-4. United State of America: Prentice Hall Inc.

Bollen, K. A. 1989. Structural Equations with Latent Variables. United State of America: A Wiley-Interscience Publication.

Brah, S. A., Tee, S. S. L., \& Rao, B. M. 2002. Relationship between TQM and Performance of Singapore Companies. International Journal of Quality \& Reliability Management. 19(4): 356-379.

Byrne, B. M. 2001. Structural Equation Modeling with AMOS: Basic Concepts, Applications, and Programming. London: Lawrence Erlbaum Associates, Publishers.

Conca, F. J., Llopis, J. \& Tari, J. J. 2004. Development of a Measure to Assess Quality Management in Certified Firms. European Journal of Operational Research. 156: 683-697.

Demirbag, M., Tatoglu, E., Tekinkus, M. \& Zaim, S. 2006. An Analysis of the Relationship Between TQM Implementation and Organizational Performance: Evidence from Turkish Smes. Journal of Manufacturing Technology Management. 17(6): 829-847. 
Dudbridge, Michael. 2011. Handbook of Lean Manufacturing in the Food Industry. Willey Blackwell. United Kingdom

Feng, M., Terziovski, M. \& Samson, D. 2008. Relationship of ISO9001:2000 Quality System Certification with Operational and Business Performance: A Survey in Australia and New Zealand-based Manufacturing and Service Companies. Journal of Manufacturing Technology Management. 19(1): 22-37.

Fotopoulos, C. B. \& Psomas, E. L. 2009. The Impact of "Soft" and "Hard" TQM Elements on Quality Management Results. International Journal of Quality \& Reliability Management. 26(2): 150-163.

Gadenne, D. \& Sharma, B. 2009. An Investigation of the Hard and Soft Quality Management Factors of Australian SMES and Their Association with Firm Performance. International Journal of Quality \& Reliability Management. 26(9):865-880.

Golomski, W. A. 1993. Total Quality Management and the Food Industry: Why Is It Important? Food Technology. May: 74-79.

Hair, J. J. F., Black, W. C., Babin, B. J., Anderson, R. E. \& Tatham, R. 2006. Multivariate Data Analysis: Ed. Ke-6. New Jersey: Pearson Prentice Hall.

Industrial Master Plan 3 (IMP3) 2006-2020. 2006. Malaysia: Percetakan Nasional Malaysia Berhad.

Jabatan Kemajuan Islam Malayia (JAKIM). 2008. Bahagian Hub Halal. Laporan statistik pensijilan Halal JAKIM.

Jang, C. L. 2010. Measuring Electronic Government Procurement Success and Testing for the Moderating Effect of Computer Self-Efficacy. International Journal of Digital Content Technology and Its Applications. 4(3/June): 224-232.

Karipidis, P., Athanassiadis, K., Aggelopoulos, S., \& Giompliakis, E. 2009. Factors Affecting the Adoption of Quality Assurance Systems in Small Food Enterprise. Food Control. 20: 93-98.

Kaynak, H. 2003. The Relationship Between Total Quality Management Practices and Their Effects on Firm Performance. Journal of Operations Management. 21: 405-435.

Kumar, V., Choisne, F., Grosbois, D., \& Kumar, U. 2009. Impact of TQM on Company's Performance. International Journal of Quality \& Reliability Management. 26(1): 23-37.

Lakhal, L., Pasin, F. \& Limam, M. 2006. Quality Management Practices and Their Impact on Performance. International Journal of Quality and Reliability Management. 23(6): 625-646.

Lee, P. M. 2002. Sustaining Business Excellence Through A Framework of Best Practices in TQM. The TQM Magazine. 14(3): 142-149.

Lewis, W. G., Pun, K. F., \& Lalla, T. R. M. 2006. Exploring Soft Versus Hard Factors for TQM Implementation in Small and Medium Sized Enterprises. International Journal of Productivity and Performance Measurement. 55(7): 539-554.

Lin, C. I. \& Jang, W. Y. 2008. Successful ISO 9000 implementation in Taiwan: How can we achieve it, and what does it mean? International Journal of Productivity and Performance Management. 57(8): 600-622.

Malaysia Productivity Corporation (MPC). 2010. Quality Management Excellence Award. http://www.mpc.gov.my [4 Februari 2010].

Manning, L. \& Baines, R. N. 2004. Effective Management of Food Safety and Quality. British Food Journal. 106(8): 598-606.

Metts, G. A. 2007. Measuring the Effectiveness of Managerial Action in SMEs: An empirical Analysis of Management's Response to Industry Competitive Forces. Management Research News. 30(12): 892-914.

Meyers, L. S., Gamst, G. \& Guarino, A. J. 2006. Applied Multivariate Research: Design and Interpretation. United State of America: Sage Publication Inc.

Ministry of Health Malaysia (MOH). 2009. Department of Food Safety and Quality. Laporan Statistik Pensijilan HACCP, GMP, GHP.

Ministry of International Trade and Industry (MITI). 2008. MITI annual report 2008. http://www.miti.gov.my [12 Februari 2011].

Mohamad A. Shukor. 2004. The Challenges in Building a Safe and Sustainable Food Industry. Policy and Development: The MultiDisiplinary Bulletin INTAN 1(1/June): 29-35.

Muslim Amin. 2009. Hubungan Kualiti Perkhidmatan Ke Atas Kepuasan Pelanggan, Kesetiaan Pelangga, Imej dan Kepercayaan Perbankan Islam di Malaysia dengan Menggunakan Pendekatan Persamaan Permodelan Berstruktur. Tesis Dr. Falsafah. Fakulti Sains dan Teknologi, Universiti Kebangsaan Malaysia.

Nor Aini Hj Idris. 2004. Cabaran Industri Pemprosesan Makanan Halal Bersaiz Kecil dan Sederhana Menghadapi AFTA. Laporan IRPA, Jabatan Ekonomi Pembangunan, Fakulti Ekonomi, Universiti Kebangsaan Malaysia.

Nor Hasni Osman. 2005. Keefisinenan dan Amalan Perniagaan Usahawan Kecil Bumiputera Di Negeri Kedah Darul Aman. Tesis Dr. Falsafah, Fakulti Sains dan Teknologi, Universiti Kebangsaan Malaysia.

Norhayati Zakuan. 2009. Structural Analysis of Total Quality Management, ISO/TS 16949 and Organizational Performance in Malaysian and
Thailand automotive industry. Tesis Dr. Falsafah. Universiti Teknologi Malaysia.

Pang, F. \& Toh, P. S. 2008. Hawker Food Industry: Food Safety/ Public Health Strategies in Malaysia. Nutrition and Food Science. 38(1): 4151.

Parast, M. M., Adams, S. G. \& Jones, E. C. 2011. Improving Operational and Business Performance in the Pertroleum Industry Through Quality Management. International Journal of Quality \& Reliability Management. 28(4): 426-450.

Pinho, J. C. 2008. TQM and Performance in Small Medium Enterprises: The Mediating Effect of Customer Orientation and Innovation. Journal of Quality and Reliability Management. 25(3): 256-275.

Puay, S. H., Tan, K. C., Xie, M. \& Goh, T. N. 1998. A Comparative Study of Nine National Quality Awards. The TQM Magazine. 10(1): 30-39.

Quazi, H. A. \& Padibjo, S. R. 1998. A Journey Toward Total Quality Management through ISO 9000 Certification: A Study on Small and Medium Sized Enterprise in Singapore. International Journal of Quality and Reliability Management. 15(5): 489-508.

Rancangan Malaysia Kesembilan (RMK9) 2006-2010. 2006. Malaysia: Unit Perancangan Ekonomi, Jabatan Perdana Menteri.

Rohitratana, K., \& Boon-itt, S. 2001. Quality standard Implementation in the Thai Seafood Processing Industry. British Food Journal. 103(9): 623630

Saemah Rahman. 2004. Hubungan Antara Metakognisi, Motivasi, dan Pencapaian Akademik Universiti. Tesis Dr. Falsafah. Kuala Lumpur: Univeristi Malaya.

Samson, D. \& Terziovski, M. 1999. The Relationship Between Total Quality Management Practices and Operational Performance. Journal of Operations Management. 17: 393-409.

Santos-Vijande, M. L. \& Alvarez-Gonzalez, L. I. 2007. TQM and Firms' performance: An EFQM Excellence Model Research Based Survey. International Journal of Business Science and Applied Management. 2(2): $21-41$.

Shah, R., \& Goldstein, S. M. 2006. Use of Structural Equation Modelling in Operations Management Research: Looking Back and Forward. Journal of Operations Management. 24: 148-169.

Sharma, M., \& Kodali, R. 2008. TQM Implementation Elements for Manufacturing Excellence. The TQM Magazine. 20(6): 599-621.

Sila, I., \& Ebrahimpour, M. 2005. Critical Linkages Among TQM Factors and Business Result. International Journal of Operations and Production Management. 25(11): 1123-1155.

Singh, P. J., Feng, M. \& Smith A. 2006. ISO 9000 Series of Standards: Comparison of Manufacturing and Service Organizations. International Journal of Quality \& Reliability Management. 23(2):122-142.

Skrinjar, R., Vusksic, V. B., \& Stemberger, M. I. 2008. The Impact of Business Process Orientation on Financial and Non-financia Performance. Business Process Management Journal. 14(5): 738-754.

Small and Medium Industries Development Corporation (SMIDEC). 2006. SMIDEC Annual Report 2006.

Spiegel, M. V. D., Lunning, P. A., Ziggers, G. W., \& Jongen, W. M. F. 2003. Towards a Conceptual Model to Measure Effectiveness of Food Quality Systems. Trend in Food Sciences and Technology. 14: 424-431.

Su, Q., Li, Z., Zhang, S. X., Liu, Y. Y. \& Dang, J. X. 2008. The Impacts of Quality Management Practices on Business Performance: An Empirica Investigation From China. Internal Journal of Quality \& Reliability Management. 25(8): 809-823.

Trienekens, J. \& Zuurbier, P. 2008. Quality and Safety Standards in the Food Industry, Developments and Challenges. International Journal of Production Economics. 113: 107-122.

Tybor, P. T., Hurst, W. C., Raynolds, A. E., \& Schuler, G. A. 1997. Quality control: A Model Program for the Food Industry. Bulletin 997: 1-12.

United Nations Industrial Development Organization (UNIDO), Vienna, Austria. 2006. Product Quality: A guide for small and medium-sized enterprise. http://www.unido.org/fileadmin/ media/documents/pdf [17 Januari 2009].

Wali, A. A., Deshmukh, S. G. \& Gupta, A. D. 2003. Critical success factors of TQM: A Select Study of Indian Organizations. Production Planning \& Control. 14(1): 3-14.

Yeung, A. C. L., Cheng, T. C. E., \& Lai, K. H. 2005. An Empirical Model for Managing Quality in the Electronics Industry. Production and Operations Managemen. 14(2/Summer): 189-204.

Yusof, M. S., \& Aspinwall, E. 2000. A Conceptual Framework for TQM Implementation for SMEs. The TQM Magazines. 2000: 12(1): 31-36.

Zaihatun, M. Z. 2003. The Implementation of Hazard Analysis and Critical Control Point (HACCP) by the Seafood Industry in Malaysia. Maritim Institute of Malaysia (MIMA) online articles. http://mima.gov.my/mima/htmls/papers/pdf/zmz/haccp.pdf $\left[\begin{array}{ll}9 & \text { Januari }\end{array}\right.$ 2009]. 